\title{
Spatio-temporal analysis of land use/land cover dynamics in Sokoto Metropolis using multi-temporal satellite data and Land Change Modeller
}

\author{
Murtala Dangulla ${ }^{1},{ }^{\star}$ Latifah Abd Munaf $^{2}$ and Firuz Ramli Mohammad ${ }^{2}$ \\ ${ }^{1}$ Department of Geography, Usmanu Danfodiyo University, Sokoto, Nigeria. \\ ${ }^{2}$ Department of Environmental Science, Universiti Putra Malaysia.
}

Received: 2019-10-19

Accapted: 2020-11-12

Keywords:

Urbanization;

LULC change;

Remote Sensing; GIS;

Landsat

Correspondent email:

latifahmanaf@upm.edu.my

\begin{abstract}
Urbanization is currently one of the most pressing environmental issues which cuts across all countries at unprecedented rates and intensities, with far reaching consequences on ecosystems, biodiversity and human wellbeing. This paper assessed urban expansion and land use/land cover changes in Sokoto metropolis, North-western Nigeria using Remote Sensing and GIS. Landsat images of 1990, 1999 and 2015 were processed for LULC classification and change detection using the Maximum Likelihood Classification, Post Classification Comparison techniques and the Land Change Modeler. The classification revealed five broad land cover classes which include Built-up Area, Farmland, Green Area, Open Space and Wetland/ Water. The Built-up and Green areas continuously increased while Farmland and Open space decreased throughout the study period. The metropolis expanded radially at a faster rate between 1999 and 2015 with the highest rate of increase (1890.5ha per annum) recorded in the Built-up Area. This implies a doubling time of approximately 30 years at the expense of Farmland and Open space which may be completely exhausted in 40 and 29 years respectively. Infrastructural provision should thus align with the rate and direction of growth and where the Green Area is converted, replacement should be made to ensure continued supply and stability of the numerous ecosystem services green areas provide.
\end{abstract}

2020 by the authors. Licensee Indonesian Journal of Geography, Indonesia.

ins of the Creative Commons

Attribution(CC BY NC) licensehttps///creativecommons.org/licenses/by-nc/4.0\%.

\section{Introduction}

Nigeria is the most populous country in Africa which was also poised to experience the highest increases in urban population (Farrell, 2018). The proportion of urban population in the country has continuously increased over the past 50 years, expediting the process of urbanization and urban expansion. Urbanization is one of the most pressing environmental issues of the present millennium. It is a natural phenomenon that involves changes in the physical and functional components of the built environment and presently cuts across all countries (Nkeki, 2016) at unprecedented rates and intensities (Bhat et al., 2017). Urban expansion occurs globally due to urban population growth and socioeconomic development in a particular area and represents the transformation of non-urban land to urban land (Jianguo, 2014). According to He et al. (2019), the global urban land increased at an annual rate of $3.5 \%$ between 1992 and 2016 which culminated into a total increase of 346.4 thousand $\mathrm{km}^{2}$ (Bloch et al., 2015) and is expected to reach $58.3 \%$ and $67.1 \%$ by 2030 and 2050 respectively (United Nations, 2014). This translates to about 10-fold expansion of cities which has been largely, unplanned and uncontrolled (Aliyu and Amadu, 2017). As a result, urban areas in Nigeria face such problems as inadequate housing and infrastructure, slum proliferation, widespread poverty and unemployment (Jianzhu and Maduako, 2018) as well as alteration of natural land surface temperature, changes in urban drainage morphology and increased surface runoff and flood events (Mahmoud et al., 2016) among others.
Sokoto metropolis has in recent times witnessed significant increases in human population and thus, accelerated expansion from the urban core (Ogunjobi et al., 2018). According to Eniolorunda and Dankani (2012), ruralurban migration and proliferation of socio-economic activities brought about by the reintroduction of democracy in Nigeria in 1999, led to continuous growth of the city. These led to significant land use/land cover changes in the city, via conversion of adjacent farmlands and open spaces into residential, commercial and institutional structures as well as roads and other infrastructure (Dangulla, 2019).

Land use/land cover (LULC) changes are the most common phenomena associated with urbanization (Xiaowei et al., 2015). These are alterations in the manner and purposes underlying human exploitation of the earth's natural or human-engineered materials (Mekonnen et al., 2018). They result from the interaction between structural and behavioural factors in relation to the technological development, demand, and social realities of a particular environment (Rawat et al., 2013) and involve both changes to a different use or in the intensity of a particular use (Goodin et al., 2015). Rapid urbanization and land use/land cover (LULC) changes play significant roles in eco- environmental changes and deterioration (Wu et al., 2016). Analysing and understanding urban LULC changes is thus crucial for the assessment of human-environment interactions (Chowdhury et al., 2019), efficient use and management of resources (Lal et al., 2017), urban planning and sustainability (Ayele et al., 
2018) and monitoring of environmental problems (Bai et al., 2017).

LULC changes were traditionally assessed with the cumbersome, expensive and time consuming field studies, census data and/or aerial photographs (Fonji and Taff, 2014). In recent times, advances in Remote Sensing (RS) and Geographic Information Systems (GIS) have provided unique opportunities for generating dynamic and repeatable land-based information on wider spatial and temporal scales (Hermosilla et al., 2015). These tools have thus become increasingly reliable for studying and monitoring urban expansions and the resultant LULC changes (Sory et al., 2018) at lower costs and higher accuracies (Fenta et al., 2017). In many studies such as Eniolorunda and Dankani (2012) and Shamaki and Dankani (2012) however, land cover of the city was merely classified over given periods without modelling future trends of these changes. The aim of this paper is therefore to analyse the spatio-temporal trends and patterns of urban expansion and LULC dynamics in Sokoto metropolis, North-western Nigeria over a 25year period using the Land Change Modeler (LCM) in RS and GIS environment. The LCM approach which is embedded in the Idrisi TerrSet software (Eastman, 2015), integrates the Multilayer-Perceptron (MLP) with the Markov Chain method to model land transition probabilities using historical LULC change data and other geospatial datasets (Iizuka et al., 2017; Mahmoud et al., 2016). Compared to many modelling approaches, the LCM is faster, more simplified and easily understandable (Eastman, 2015; Nor et al., 2017).

\section{The Methods}

\section{The Study Area}

Sokoto metropolis is located on latitudes $13^{\circ} 03^{\prime} 05^{\prime \prime} \mathrm{N}$ and longitudes $05^{\circ} 13^{\prime} 53^{\prime \prime} \mathrm{E}$ and covers approximately $94 \mathrm{~km}^{2}$ (Figure 1). The city occupies high administrative and educational positions in the country being the headquarters of the Sokoto Caliphate (AD 1809) and later Sokoto State since 1976 (Wali, 2010). It has a projected population of 554,

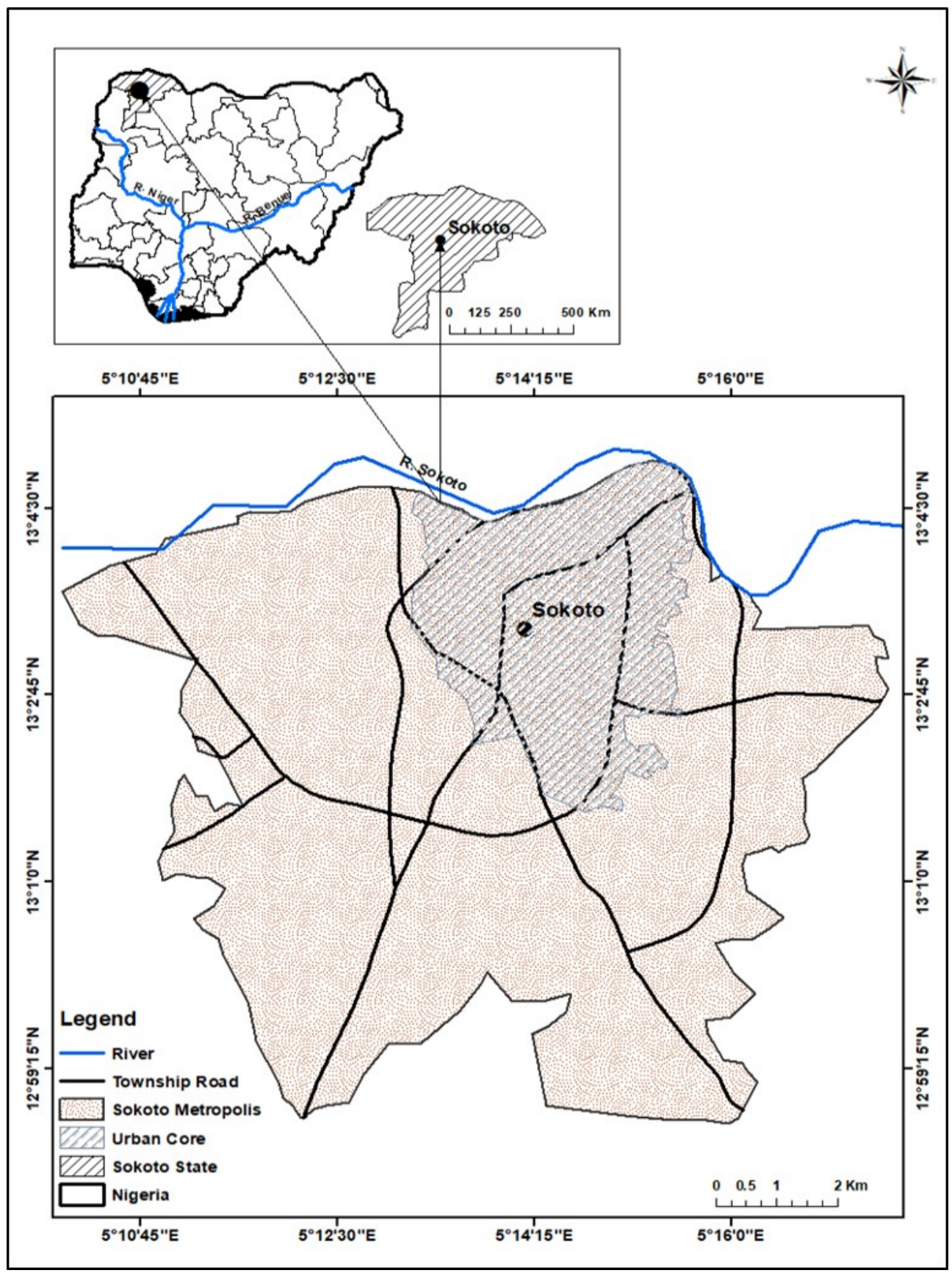

Figure 1. Sokoto metropolis and urban core (inset Nigeria and Sokoto State) 


\section{5 (National Bureau of Statistics, 2016).}

The climate is semi-arid, coinciding with the Koppen's tropical wet and dry (Aw) climate. Mean temperature ranges between $26^{\circ} \mathrm{C}$ and $28^{\circ} \mathrm{C}$ while rainfall ranges between $508 \mathrm{~mm}$ and $1,016 \mathrm{~mm}$ (Sanni et al., 2012). Vegetation is the SudanoSahelian type, composed of grasses and sparsely distributed, drought tolerant tree species (Karlson and Ostwald, 2016). The soils are generally ferruginous, light and of low nutrient value (Wezel and Lykke, 2006).

\section{Data Acquisition and Processing}

Landsat imageries for the years 1990, 1999 and 2015 for the metropolis (Path/Row 191/051) were obtained from the United States Geological Survey (www.earthexplorer.usgs.gov) and primarily used for the study. Landsat data has been extensively used in LULC change analyses due to its consistent, global coverage and archive since 1972 and free availability since 2008 (Wulder et al., 2012). The images were acquired in the dry season to minimize cloud cover and at near-anniversary to limit the effects of seasonal variations on the classification (Lal et al., 2017). The various images used in this study are presented in Table 1.

\section{Image Pre-processing}

Image pre-processing involves removal or minimization of distortions introduced to satellite images due to sensor, solar, atmospheric and topographic effects. This is to enhance the quality and interpretability of the image components for remote sensing analysis (Sowmya et al., 2017). The study area was first clipped from the respective images and then orthorectified to the UTM $31 \mathrm{~N}$ projection and WGS 84 datum so that each point of the image matches each corresponding point on the ground. The image digital numbers (DNs) were converted to At-sensor radiance and to Top of Atmosphere (TOA) reflectance while the COST model (Chavez, 1996) was employed for atmospheric correction. Due to sensor difference, geometric correction was also carried out. The 1990 and 1999 images were coregistered to the 2015 image which was taken as the reference image. The operation revealed an RMSE of $0.134(\approx 4 \mathrm{~m})$.

\section{Image Classification}

We adopted the widely used Maximum Likelihood Classification (MLC) (Al-doski et al., 2013; Jawak et al., 2015) and the modified Anderson's Level 1 classification. MLC classifies image pixels based on the highest probability of belonging to a particular class (Shi and Xue, 2017) and minimises misclassification errors by allowing variable weight specifications during the classification process (Abudu et al., 2019). This approach was preferred for its enhanced accuracy (Hasmadi et al., 2009), operational simplicity, easy applicability and performance (Lillesand and Kiefer, 2015).
It is given as:

$$
g_{i}(x)=\ln p\left(\omega_{i}\right)-1 / 2 \ln \left|C_{i}\right|-1 / 2\left(x-m_{i}\right)^{t} C_{i}^{-1}\left(x-m_{i}\right)
$$

where:

- $\mathrm{g}_{\mathrm{i}}(\mathrm{x})=$ likelihood that $\mathrm{x}$ belongs to class $\omega_{i}$

- $c_{\mathrm{i}}$ and $\mathrm{m}_{\mathrm{i}}=$ sample estimates of covariance and mean in class ${ }^{\omega_{i}}$ and

- $\mathrm{p}\left({ }^{\omega_{i}}\right)=$ class probability

A total of 200 pixels were selected across the metropolis using the stratified sampling module of Idrisi TerrSet software and their coordinates imputed into the waypoint list of a Garmin GPS. These were used as sample points for ground data collection and training sites for supervised classification.

\section{Accuracy Assessment}

To ensure the accuracy of remote sensing image classification, accuracy assessment is traditionally carried out to quantitatively assess how effectively the pixels were sampled into the correct land cover classes (Rwanga and Ndambuki, 2017). In this study, this was achieved by assessing the overall, producer and user accuracies of the maps using the confusion matrix and Kappa coefficient (Foody, 2015). An additional 150 pixels (Chowdhury et al., 2019) were selected for assessing the accuracy of 2015 image while the 1990 and 1999 images were assessed with the historical images of Google Earth as obtained from Pellikka et al. (2018). The matrix table was then developed for each year. The confusion matrix and Kappa coefficient were calculated as:

User accuracy $=\frac{\text { Number of Correctly Classified Pixles in a class }}{\text { Total Number of Pixles in a class }}$
Producer's accuracy $=\frac{\text { Number of Correctly Classified Pixles in a class }}{\text { Total Number of Pixles in all classes }}$
Overall accuracy $=\frac{\text { Total Number of all Correctly Classified Pixles }}{\text { Total Number of Pixles in all classes }}$
\[ \frac{N \sum_{i=1}^{n} m_{i, i}-\sum_{i=1}^{n}\left(G_{i} C_{i}\right)}{N^{2}-\sum_{i=1}^{n}\left(G_{i} C_{i}\right)} \]

Table 1. Landsat data for Sokoto metropolis (Path 191/Row 051) used in the study

\begin{tabular}{lllcc}
\hline S/N & Landsat Image & Sensor & Spatial Resolution & Date of Acquisition \\
\hline 1. & Landsat 5 & TM & $30 \mathrm{~m}$ & $27 / 12 / 1990$ \\
2. & Landsat 7 & ETM $^{+}$ & $30 \mathrm{~m}$ & $18 / 11 / 1999$ \\
3. & Landsat 8 & OLI TIRS & $30 \mathrm{~m}$ & $22 / 11 / 2015$ \\
\hline
\end{tabular}




\section{Change Detection}

Change detection was carried out using the Post Classification Comparison (PCC) which is the most popular and most accurate change detection approach (Mallupattu et al., 2013). PCC describes the nature of changes between study epochs while minimizing the problem of radiometric calibration between images of different dates (Wang, 2012). The proportion of each LULC class was calculated for each year and the changes between the respective years were determined.

\section{Rate and pattern of LULC Change}

The rate of LULC change in the metropolis during the study period (1990 - 2015) was determined using the formula obtained from Pham et al. (2015) as follows:

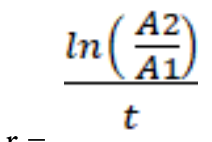

where:

$\mathrm{r}=$ rate of change

$\mathrm{A} 1=$ area extent of LULC the initial time $(\mathrm{t} 1)$

$\mathrm{A} 2=$ area extent of LULC at later time (t2)

$\ln =$ natural $\log$

$\mathrm{t}=\mathrm{t} 2-\mathrm{t} 1$

The pattern of LULC changes as well as the matrix of change between the LULC classes, were assessed using the Land Change Modeler (LCM) embedded in the Idrisi TerrSet software (Areendran et al., 2017). The Cubic trend analysis was used to show the pattern of land use conversion from the city center while the interchange between individual land use/cover classes was derived from the transition matrix generated with the software.

\section{Results and Discussion LULC classification}

Based on the Anderson Level I classification scheme, the Maximum Likelihood Classification employed in this study revealed five broad LULC classes in the metropolis which include the Built-up Area (BUA), Farmland (FL), Green Area (GA), Open Space (OS) and Wetland/Water (WWT). Wetland and water bodies were merged into one LULC class because it was difficult to differentiate these bodies in view of their relatively small proportion in the metropolis. The respective LULC classes are described in Table 2.

\section{Classification Accuracy Assessment}

The overall classification accuracy of the final maps was $91.7 \%, 92.1 \%$ and $90.3 \%$ for 1990,1999 and 2015 respectively. The user and producer accuracies however varied between the LULC classes and study years. In 1990, higher producer accuracy of $95.9 \%$ and lower user accuracy of $45.3 \%$ were achieved in the Wetland/water area. The higher producer accuracy obtained in this LULC class could be due to their very low spectral confusion while the lower user accuracy could be attributable to the relatively poor quality of the 1990 image (Landsat 5) used in the classification. In 1999, both user and producer accuracies were highest in the Farmland area while in 2015, the highest user accuracy was obtained in the Built-up area and the highest producer accuracy was

Table 2. Description of LULC classes in Sokoto metropolis

\begin{tabular}{ll}
\hline LULC & Description \\
\hline Built-up Area & Residential, institutional, commercial, industrial, transportation and other built areas. \\
Farmland & Rainfed crop area, irrigated and fallow lands \\
Green Area & Planted and artificial trees, shrubs and grasses \\
Open Space & Open spaces, bare surfaces, exposed soils and rocks, undeveloped plots and playing grounds \\
Wetland/Water & Rivers, ponds, reservoirs and marshy areas \\
\hline
\end{tabular}

Table 3. Classification accuracy assessment (\%) of final land cover maps for 1990, 1999 and 2015 in Sokoto Metropolis

\begin{tabular}{lllllll}
\hline \multirow{2}{*}{ LULC } & \multicolumn{2}{c}{1990} & \multicolumn{2}{c}{1999} & \multicolumn{3}{c}{2015} \\
\cline { 2 - 7 } & UA & PA & UA & PA & UA & PA \\
\hline Built-up Area & 94.7 & 93.4 & 94.3 & 93.4 & 95.9 & 89.6 \\
Farmland & 95.8 & 91.8 & 97.3 & 93.9 & 87.7 & 92.8 \\
Open Space & 82.9 & 89.4 & 82.7 & 90.6 & 75.4 & 87.7 \\
Green Area & 93.9 & 90.8 & 88.2 & 86.4 & 93.5 & 92.5 \\
Wetland/Water & 45.3 & 97.5 & 68.4 & 87.8 & 74.4 & 100.0 \\
Overall Accuracy & 91.7 & & 92.1 & & 90.3 & \\
Kappa Coefficient & 0.93 & & 0.93 & & 0.91 & \\
\hline
\end{tabular}

$\mathrm{UA}=$ User Accuracy; PA = Producer Accuracy 
obtained in the Wetland/water area. The Landsat 8 (OLI TIR) image used for LULC classification in 2015 has a better spectral quality which allowed the identification of built-up areas and water bodies (Table 3).

According to Anderson et al. (1976), an overall classification accuracy of $85 \%$ is recommended which implies that the overall accuracy achieved for this study is acceptable since this has been achieved in all the final classified maps. The study also achieved overall Kappa coefficient of 0.93 in both 1990 and 1999 and 0.91 in 2015 which shows that there is a strong agreement between the classified maps and the ground reality (John et al., 2020; Rwanga and Ndambuki, 2017). The final classified maps of the metropolis for 1990 , 1999 and 2015 are shown in figure 2 (a, b and c).

\section{LULC Changes}

Using the Post Classification Comparison, changes in LULC between 1990 and 1999 and between 1999 and 2015 in the metropolis were detected. In 1990 which is the base year, FL occupied the largest percentage $(38.2 \%)$ of the total area (3608ha), followed by the BUA which occupied $25.4 \%$ (2400ha) and OS which occupied 21\% (1972.5ha). The GA
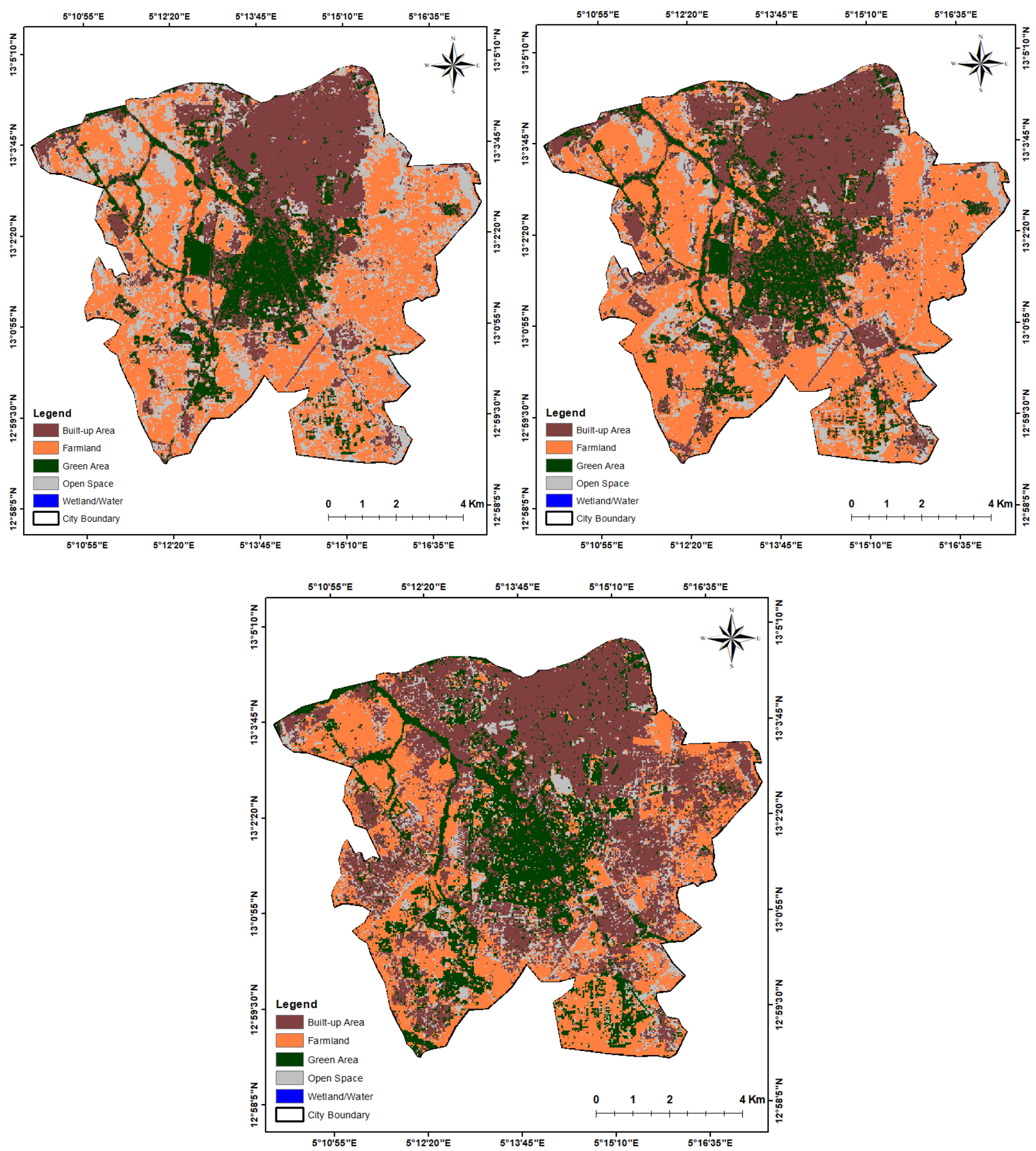

Figure 2. Final classified LULC maps for 1990 (a), 1999 (b) and 2015 (c) 
and WWT on the other hand occupied 13.7 and $1.8 \%$ of the total area (1290.5 and 172 hectares) respectively. By the year 1999, the pattern of LULC changed with noticeable increases in all the LULC classes except the OS. FL expanded a little to occupy $39 \%$ of the total area while the BUA expanded by 382.5 ha to occupy $39 \%$. The GA increased by 18.5 ha to occupy $13.9 \%$ of the area while WWT increased by 123.5 ha to occupy $3.1 \%$. Conversely, OS decreased by approximately 600 ha and thus, decreased to $14.5 \%$ of the total area. Between 1999 and 2015, the BUA further expanded by 1508 ha into the neighbouring farmlands and open spaces to occupy $45.4 \%$ of the total urban area while the GA appreciated by 116 ha to occupy $15.1 \%$ of the area. On the other hand, FL, OS and WWT decreased by $1300,287.6$ and 36.5 hectares respectively. Correspondingly, these land cover classes occupied 25.2, 11.5 and $2.7 \%$ of the total urban land respectively by the year 2015 (Table 4).

Overall LULC gains and losses during the study period (1990-2015) showed that approximately 2100ha have been transformed from one LULC to another. The gains were recorded in the BUA, WWT and GA while losses were recorded in the FL and OS. The highest net gain of 1890.5 ha was recorded in the BUA while the GA and WWT gained
134.4 and 87 hectares respectively. On the other hand, FL lost a cumulative 1225.3 ha while OS lost 886.7 ha (Figure 3 ).

\section{Rate and Pattern of LULC Change}

The annual rate of LULC change was generally slow between 1990 and 1999 with the exception of WWT which increased at $6.01 \%$ (10.3ha) per annum. During this period, the BUA increased at $1.64 \%$ (39.4ha), the FL increased at $0.23 \%$ (8.2ha) while the GA increased at $0.16 \%$ (2.0ha) per annum. Conversely, the OS decreased at $4.02 \%$ (79.3ha) per annum. Between 1999 and 2015, the rate of LULC change in the metropolis increased considerably. The BUA increased at $2.71 \%$ (65.0ha) and the GA increased at $0.53 \%$ (6.8ha) per annum. On the contrary, the FL, OS and WWT decreased at 2.72 (98.2ha), 1.47 (29.0ha) and $0.82 \%$ (1.4ha) respectively.

The overall average rate of change (1990-2015) was 2.3\% (59ha) increase in the BUA and $1.7 \%$ decrease (60ha) in the FL per annum. The OS decreased rapidly at $4 \%$ (79.3ha) between 1990 and 1999 but slowed down to 1.5\% (29ha) between 1999 and 2015. Interestingly, GA and WWT increased throughout the study period with the overall rate of increase at $0.4 \%$ and $1.6 \%$ (5.1 and 2.8 hectares) respectively (Table 5).

Table 4. Composition of LULC types and their percentage changes between 1990 and 2015 (ha)

\begin{tabular}{lllllllll}
\hline LULC & 1990 & $\%$ & 1999 & $\%$ & 2015 & $\%$ & Change & $\%$ \\
\hline Built-up Area & 2400.0 & 25.4 & 2782.5 & 29.5 & 4290.6 & 45.4 & 1890.5 & $78.8 \%$ \\
Farmland & 3607.9 & 38.2 & 3682.5 & 39.0 & 2382.7 & 25.2 & -1225.3 & $-34.0 \%$ \\
Open Space & 1972.5 & 20.9 & 1373.5 & 14.5 & 1085.9 & 11.5 & -886.7 & $-45.0 \%$ \\
Green Area & 1290.5 & 13.7 & 1309.0 & 13.9 & 1424.9 & 15.1 & 134.4 & $10.4 \%$ \\
Wetland/Water & 171.9 & 1.8 & 295.4 & 3.1 & 258.9 & 2.7 & 87.0 & $50.6 \%$ \\
& 9442.9 & 100 & 9442.9 & 100 & 9442.9 & 100 & & \\
\hline
\end{tabular}

Figure 3. Net gains and losses in land use/cover in Sokoto metropolis between 1990 and 2015 (hectares)

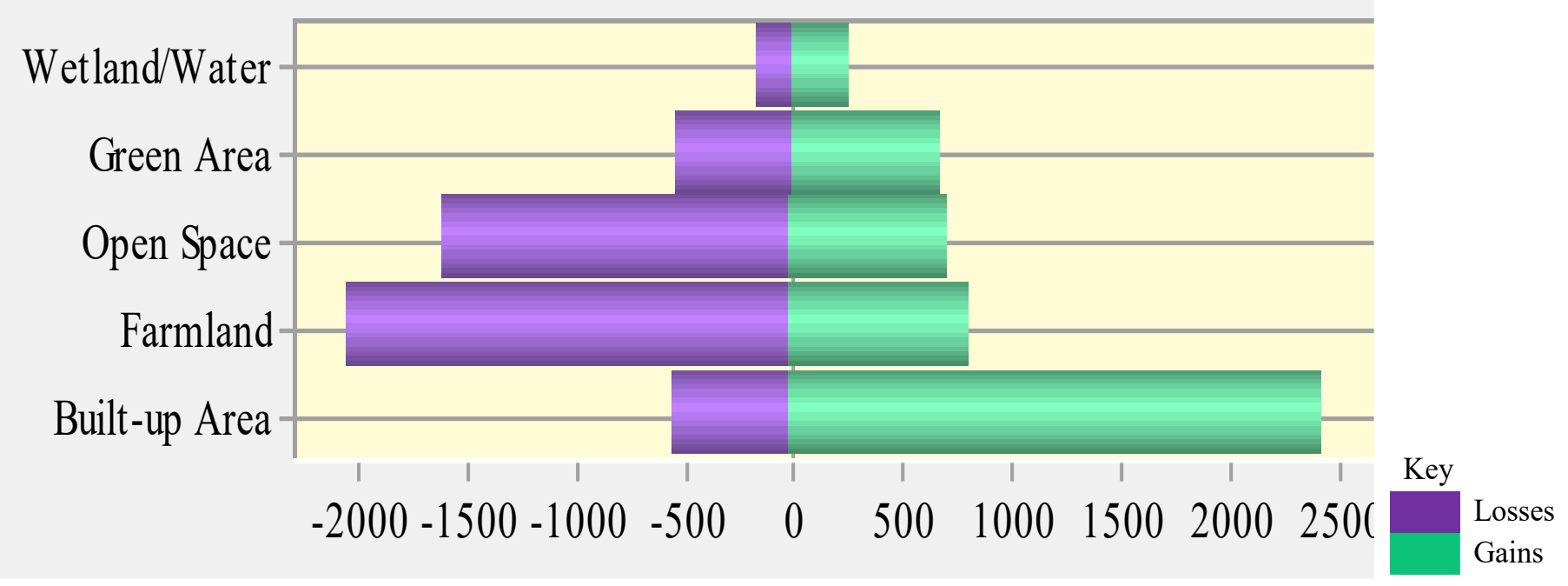


Table 5. Average annual rate of LULC change in Sokoto Metropolis - 1990 to 2015 (Hectare)

\begin{tabular}{lcccccc}
\hline \multirow{2}{*}{ LULC } & \multicolumn{2}{c}{$1990-1999$} & \multicolumn{2}{c}{$1999-2015$} & \multicolumn{2}{c}{ Overall (1990-2015) } \\
\cline { 2 - 7 } & Ha & $\%$ & Ha & $\%$ & Ha & $\%$ \\
\hline Built-up Area & 39.4 & 1.64 & 65.0 & 2.71 & 55.8 & 2.3 \\
Farmland & 8.2 & 0.23 & -98.2 & -2.72 & -59.9 & -1.7 \\
Open Space & -79.3 & -4.02 & -29.0 & -1.47 & -47.1 & -2.4 \\
Green Area & 2.0 & 0.16 & 6.8 & 0.53 & 5.1 & 0.4 \\
Wetland/Water & 10.3 & 6.01 & -1.4 & -0.82 & 2.8 & 1.6 \\
\hline
\end{tabular}

\section{Discussion}

The spatial pattern of LULC conversion in the metropolis was radial as it occurred in all directions. This is however more pronounced to the North-western and South-western sides where development lands were supposedly more accessible. The OS and FL were the most vulnerable LULC classes as the metropolis expanded. While conversion of OS inclined to the Eastern and Southern sides, conversion of FL areas was more to the North-west and South-west. Farmlands in the first three concentric zones around the urban core were severely converted during the study period while conversions continued towards the fourth and fifth concentric zones. This followed the natural urban development process where cities expand along ring roads from city center to the fringe, as obtained in Changchun (Zhang et al., 2016) and Chengdu cities of China (Peng et al., 2015). The pattern and trend of land cover conversions in the metropolis is shown by the cubic trend analysis (Figure 4a and b).

Rapid population growth and land use/cover changes are some of the major challenges of urban areas in developing countries with profound negative impacts on agricultural lands, vegetation and other valuable habitats (Abudu et al., 2019; Jianzhu and Maduako, 2018). On a spatial scale, our study revealed that Sokoto metropolis expanded radially but more to the north-western, southern and eastern parts, eating into the available farmlands and open spaces. On a temporal scale, the metropolis expanded faster between 1999 and 2015. The BUA expanded at the rate of $1.6 \%$ between 1990 and 1999 but at $2.71 \%$ between 1999 and 2015. This implied that, the metropolis will double its present size by $2045 \quad(\approx 30$ years). As observed by McGovern and Pasher (2016) and Wang and Maduako (2018) among others, most LULC conversions affect agricultural lands, vegetation and other natural land cover. In this study, OS and FL which decreased at 2.4 and $1.7 \%$ respectively, were largely converted to BUA and a large vegetation patch was converted for a residential project. Based on the "Rule of 70" (Donnermeyer, 2015), OS may be totally converted in approximately 29 years while adjacent farmlands may be totally absorbed in $\approx 40$ years (Figure 5).

It was also observed that some parcels of the BUA and GA were converted to OS while many others were converted to GA. The former trend was accounted for by some of the construction projects executed in the metropolis such as dualization of township roads which led to the clearance of many street trees and shops. In the latter case, peoples' efforts at planting trees or introductions of non-native species

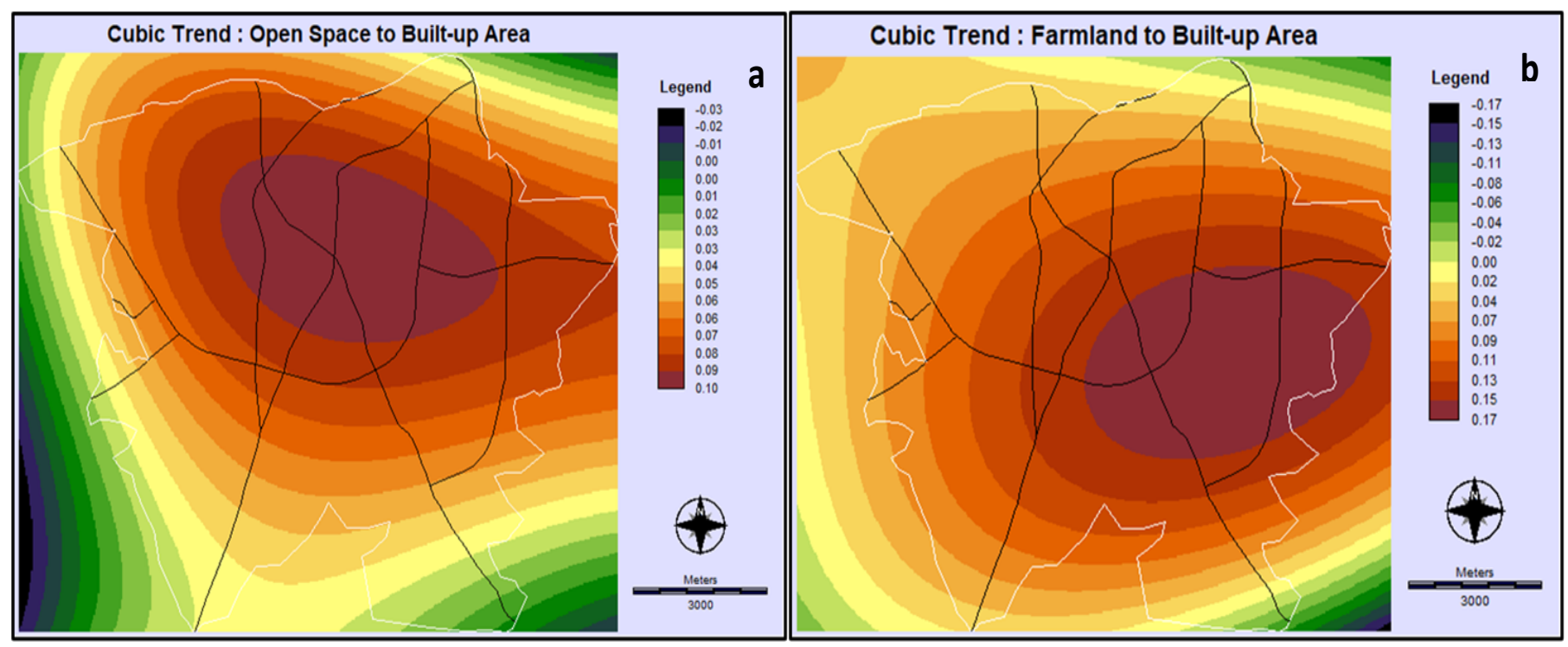

Figure 4. Pattern and trend of land cover conversions from (a) OS to BUA and (b) FL to BUA 

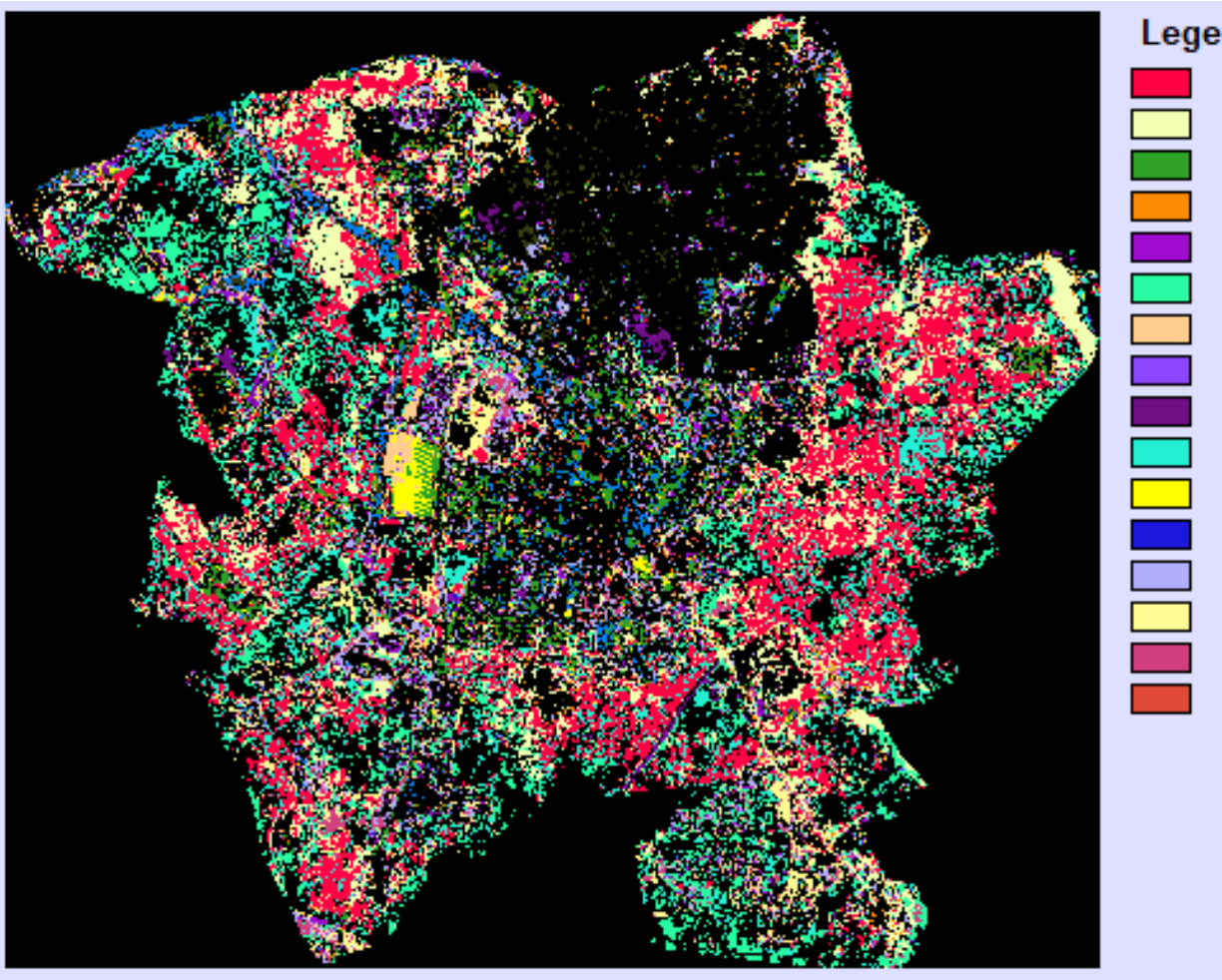

Farmland to Built-up Area

Open Space to Built-up Area

Green Area to Built-up Area

Wetland/Water to Built-up Area

Built-up Area to Farmland

Open Space to Farmland

Green Area to Farmland

Wetland/Water to Farmland

Built-up Area to Open Space

Farmland to Open Space

Green Area to Open Space

Wetland/Water to Open Space

Built-up Area to Green Area

Farmland to Green Area

Open Space to Green Area

Wetland/Water to Green Area

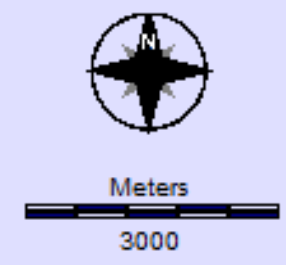

Figure 5. Transition matrix of LULC in Sokoto metropolis between 1990 and 2015

especially in new residential areas and other private lands for shade and beautification as also opined by Blood et al. (2016), greatly increased tree species richness and density in the metropolis. In addition, the natural growth of existing trees invariably increases the percentage of tree canopy cover (McGovern and Pasher, 2016) which was captured by the satellite sensor during the 25year study period. Similar results were obtained by Sinha et al. (2016) in Adama Municipal Area, Ethiopia.

The rate of urban expansion recorded in this study is however, slower than what was reported in other cities. In Kaduna for instance, Akpu and Tanko (2017) reported an annual increase of 5.72\%. Mahmoud et al (2016) reported that the Federal Capital Territory (FCT) Abuja expanded at $6.31 \%$ between 2001 and 2014 while Jos expanded at $6.7 \%$ (Akintunde et al., 2016). Higher annual growth rates of 5.6\% and $4.2 \%$ were also reported in Rustenburg, South Africa (Mudau et al., 2014) and Fez, Morocco (El Garouani et al., 2017). This may however not be surprising as these cities are larger and perform higher socio-economic functions than Sokoto metropolis.

The predominance of agriculture as the main source of employment and livelihood for about $80 \%$ of the people in Northern Nigeria (Macaulay, 2014) implied that FL was the dominant LULC around Sokoto metropolis. With growing human population however, there was increased need for shelter, infrastructure and other commercial facilities which accounted for the expansion of the city and loss of adjacent farmlands. The total population was 2, 418, 585 in 1991 but rose to 3, 702, 676 in 2006 and to 4,998,090 in 2016, implying an increase of about $48.4 \%$ in 25 years (Nigeria Population Council, 2007). Conversion of farmlands recorded in this study tallied with what was reported in many cities such as Lagos and Abidjan (Nlend et al., 2018), Hyderabad (Gumma et al., 2017), Riyadh (Alqurashi and Kumar, 2017) and Hanoi (Pham et al., 2015) among others, where loss of valuable agricultural lands was related to population increase and urban expansion.

Expansions of urban areas are variously shown to adversely affect ecosystems and biodiversity through fragmentation and habitat loss (Delphin et al., 2016), vegetation degradation ( $\mathrm{Li}$ et al., 2015) and alteration in the distribution and pattern of surrounding energy cycles leading to urban heat island phenomenon (Schneider et al., 2012). In Nigeria, urban expansions were attributable to accelerated rural-urban migrations and higher fertility rates which brought about health crises among city dwellers especially the urban poor (Aliyu and Amadu, 2017). Similarly, vegetation degradation due to continued urban expansion may potentially trigger flash flood events especially in areas with deficient drainage systems (Mahmoud et al., 2016).

\section{Conclusion}

This study highlighted the usefulness of RS and GIS in mapping and detecting urban LULC dynamics at both spatial and temporal scales. Multi-temporal Landsat data has also been shown to accurately detect urban LULC changes despite their moderate spatial resolutions. Although the MLC is a widely used LULC classification technique, it has been shown to perform better when combined with the LCM. Farmland was the dominant LULC class around the metropolis but was extensively converted to serve the increasing demands of residential, institutional and commercial spaces of the people. Analysis with the Land Change Modeler also showed that the metropolis expanded radially but more to the northwestern, southern and eastern parts. At the present rate, the metropolis will double its size in approximately 30 years at the expense of FL and OS which were generally more 
vulnerable as the city expanded. This will have profound implications for urban planning and sustainability. Infrastructural provision should thus align with this pattern and, where GA is converted, measures should be taken to ensure replacement so that the numerous ecosystems services that urban vegetation provide are guaranteed.

\section{Acknowledgements}

This research was supported by Universiti Putra Malaysia (Grant No. GCS15-4002). We also acknowledge the United States Geological Survey (USGS) for freely providing the Landsat data used in the study.

\section{References}

Abudu, D., Echima, R. A., and Andogah, G. (2019). Spatial assessment of urban sprawl in Arua Municipality, Uganda. Egyptian Journal of Remote Sensing and Space Science, 22(3), 315-322. https://doi.org/10.1016/j.ejrs.2018.01.008

Akintunde, J. A., Adzandeh, E. A., and Fabiyi, O. O. (2016). Spatiotemporal pattern of urban growth in Jos Metropolis, Nigeria. Remote Sensing Applications: Society and Environment, 4, 4454. https://doi.org/10.1016/j.rsase.2016.04.003

Akpu, B., and Tanko, A. I. (2017). Determining the Rate and Pattern of the Spatio-Temporal Growth of Kaduna Metropolis, Kaduna State Nigeria. Journal of Geography, Environment and Earth Science International, 11(1), 1-10. https:// doi.org/10.9734/JGEESI/2017/31455

Al-doski, J., Mansor, S. B., and Shafri, H. Z. M. (2013). Change Detection Process and Techniques. Civil and Environmental Research, 3(10), 37-46. https://doi.org/10.7176/CER.

Aliyu, A., and Amadu, L. (2017). Urbanization, cities, and health: The challenges to Nigeria - A review. Annals of African Medicine, 16(4), 149. https://doi.org/10.4103/aam.aam_1_17

Alqurashi, A. F., and Kumar, L. (2017). An assessment of the impact of urbanization and land use changes in the fast-growing cities of Saudi Arabia. Geocarto International, 34(1), 78-97. https://doi.org/10.1080/10106049.2017.1367423

Anderson, J. R., Hardy, E. E., Roach, J. T., Witmer, R. E., and Peck, D. L. (1976). A Land Use And Land Cover Classification System For Use With Remote Sensor Data. A Revision of the Land Use Classification System as Presented in U.S. Geological Survey Circular 671, 964, 41.

Areendran, G., Raj, K., Mazumdar, S., and Sharma, A. (2017). Land use and land cover change analysis for Kosi river wildlife corridor in Terai Arc landscape of Northern India: Implications for future management. Tropical Ecology, 58(1), 139-149.

Ayele, G. T., Tebeje, A. K., Demissie, S. S., Belete, M. A., Jemberrie, M. A., Teshome, W. M., Mengistu, D. T., and Teshale, E. Z. (2018). Time series land cover mapping and change detection analysis using geographic information system and remote sensing, Northern Ethiopia. Air, Soil and Water Research, 11, 1-18. https://doi.org/10.1177/1178622117751603

Bai, X., Sharma, R. C., Tateishi, R., Kondoh, A., Wuliangha, B., and Tana, G. (2017). A Detailed and High-Resolution Land Use and Land Cover Change Analysis over the Past 16 Years in the Horqin Sandy Land, Inner Mongolia. Mathematical Problems in Engineering, 2017, 1-13. https:// doi.org/10.1155/2017/1316505

Bhat, P. A., Shafiq, M. ul, Mir, A. A., and Ahmed, P. (2017). Urban sprawl and its impact on landuse/land cover dynamics of Dehradun City, India. International Journal of Sustainable Built Environment, 6(2), 513-521. https://doi.org/10.1016/ j.ijsbe.2017.10.003

Bloch, R., Monroy, J., and Fox, S. (2015). Urbanisation and Urban Expansion in Nigeria (Issue July).

Blood, A., Starr, G., Escobedo, F., Chappelka, A., and Staudhammer,
C. (2016). How Do Urban Forests Compare®? Tree Diversity in Urban and Periurban Forests of the Southeastern US. Forests, 7(6), 1-15. https://doi.org/10.3390/f7060120

Chavez, P. S. (1996). Image based atmospheric corrections revisited and revised. Photogrammetric Engineering and Remote Sensing, 62(9), 1025-1036.

Chowdhury, M., Hasan, M. E., and Abdullah-Al-Mamun, M. . (2019). Land use/land cover change assessment of Halda watershed using remote sensing and GIS. The Egyptian Journal of Remote Sensing and Space Sciences, (in press). https://doi.org/https://doi.org/10.1016/j.ejrs.2018.11.003

Dangulla, M. (2019). Land cover change impacts on the tree density and carbon stock in Sokoto Metropolis, North-Western Nigeria (Issue May). Universiti Putra Malaysia.

Delphin, S., Escobedo, F. J., Abd-Elrahman, A., and Cropper, W. P. (2016). Urbanization as a land use change driver of forest ecosystem services. Land Use Policy, 54, 188-199. https:// doi.org/10.1016/j.landusepol.2016.02.006

Donnermeyer, J. F. (2015). Doubling Time and Population Increase of the Amish. Journal of Amish and Plain Anabaptist Studies, 3(1), 94-109. https://doi.org/10.18061/1811/69364

Eastman, J. R. (2015). TerrSet: Geospatial Monitoring and Modeling Software. In Clark Labs (Vol. 53, Issue 9). Clark Labs.

El Garouani, A., Mulla, D. J., El Garouani, S., and Knight, J. (2017). Analysis of urban growth and sprawl from remote sensing data: Case of Fez, Morocco. International Journal of Sustainable Built Environment, 6(1), 160-169. https:// doi.org/10.1016/j.ijsbe.2017.02.003

Eniolorunda, N. B., and Dankani, I. M. (2012). Assessment of urban growth pattern in sokoto metroplis, nigeria using multitemporal sateelite data. Nigeria Geographical Journal, 8 (1), 107-122.

Farrell, K. (2018). An Inquiry into the Nature and Causes of Nigeria's Rapid Urban Transition. Urban Forum, 29(3), 277298. https://doi.org/10.1007/s12132-018-9335-6

Fenta, A. A., Yasuda, H., Haregeweyn, N., Belay, A. S., Hadush, Z., Gebremedhin, M. A., and Mekonnen, G. (2017). The dynamics of urban expansion and land use/land cover changes using remote sensing and spatial metrics: The case of Mekelle city of northern Ethiopia. International Journal of Remote Sensing, 38(14), 4107-4129. https:// doi.org/10.1080/01431161.2017.1317936

Fonji, S. F., and Taff, G. N. (2014). Using satellite data to monitor land-use land-cover change in North-eastern Latvia. SpringerPlus, 3(1), 1-15. https://doi.org/10.1186/2193-1801-3 $-61$

Foody, G. M. (2015). Valuing map validation: The need for rigorous land cover map accuracy assessment in economic valuations of ecosystem services. Ecological Economics, 111, 23-28. https://doi.org/10.1016/j.ecolecon.2015.01.003

Goodin, D. G., Anibas, K. L., and Bezymennyi, M. (2015). Mapping land cover and land use from object-based classification: an example from a complex agricultural landscape. International Journal of Remote Sensing, 36(18), 4702-4723. https:// doi.org/10.1080/01431161.2015.1088674

Gumma, M. K., Mohammad, I., Nedumaran, S., Whitbread, A., and Lagerkvist, C. J. (2017). Urban sprawl and adverse impacts on agricultural land: A case study on Hyderabad, India. Remote Sensing, 9(11), 1-16. https://doi.org/10.3390/rs9111136

Hasmadi, M. I., Pakhriazad, H. . Z., and Shahrin, M. F. (2009). Evaluating supervised and unsupervised techniques for land cover mapping using remote sensing data. Malaysian Journal of Society and Space, 5(1), 1-10.

He, C., Liu, Z., Gou, S., Zhang, Q., Zhang, J., and Xu, L. (2019). Detecting global urban expansion over the last three decades using a fully convolutional network. Environmental Research Letters. https://doi.org/10.1088/1748-9326/aaf936

Hermosilla, T., Wulder, M. A., White, J. C., Coops, N. C., and Hobart, G. W. (2015). An integrated Landsat time series protocol for change detection and generation of annual gapfree surface reflectance composites. Remote Sensing of 
Environment, 158, 220-234. https://doi.org/10.1016/ j.rse.2014.11.005

Iizuka, K., Johnson, B. A., Onishi, A., Magcale-Macandog, D. B., Endo, I., Bragais, M., Millington, A., Nagendra, H., and Kopecka, M. (2017). Modeling Future Urban Sprawl and Landscape Change in the Laguna de Bay Area, Philippines. Land, 6(26), 1-20. https://doi.org/10.3390/land6020026

Jawak, S. D., Devliyal, P., and Luis, A. J. (2015). A Comprehensive Review on Pixel Oriented and Object Oriented Methods for Information Extraction from Remotely Sensed Satellite Images with a Special Emphasis on Cryospheric Applications. Advances in Remote Sensing, 04(03), 177-195. https:// doi.org/10.4236/ars.2015.43015

Jianguo, W. (2014). Urban ecology and sustainability: The state-ofthe-science and future directions. Landscape and Urban Planning, $\quad 125, \quad 209-221 . \quad$ https://doi.org/10.1016/ j.landurbplan.2014.01.018

Jianzhu, W., and Maduako, I. N. (2018). Spatio-temporal urban growth dynamics of Lagos Metropolitan Region of Nigeria based on Hybrid methods for LULC modeling and prediction. European Journal of Remote Sensing, 51(1), 251265. https://doi.org/10.1080/22797254.2017.1419831

John, J., Bindu, G., Srimuruganandam, B., Wadhwa, A., and Rajan, P. (2020). Land use/land cover and land surface temperature analysis in Wayanad district, India, using satellite imagery. Annals of GIS, 1-18. https:// doi.org/10.1080/19475683.2020.1733662

Karlson, M., and Ostwald, M. (2016). Remote sensing of vegetation in the Sudano-Sahelian zone: A literature review from 1975 to 2014. Journal of Arid Environments, 124, 257-269. https:// doi.org/10.1016/J.JARIDENV.2015.08.022

Lal, K., Kumar, D., and Kumar, A. (2017). Spatio-temporal landscape modeling of urban growth patterns in Dhanbad Urban Agglomeration, India using geoinformatics techniques. The Egyptian Journal of Remote Sensing and Space Sciences, 20(1), 91-102. https://doi.org/10.1016/ j.ejrs.2017.01.003

Li, G. Y., Chen, S. S., Yan, Y., and Yu, C. (2015). Effects of Urbanization on Vegetation Degradation in the Yangtze River Delta of China: Assessment Based on SPOT-VGT NDVI. Journal of Urban Planning and Development, 141(4), 05014026:1-11. https://doi.org/10.1061/(ASCE)UP.19435444.0000249

Lillesand, R. W., and Kiefer, T. M. (2015). Remote sensing and Image Interpretation. In John Wiley and Sons, Inc., New York. https://doi.org/10.1017/S0016756800012024

Macaulay, B. M. (2014). Land degradation in Northern Nigeria: The impacts and implications of human-related and climatic factors. African Journal of Environmental Science and Technology, 8(5), 267-273. https://doi.org/10.5897/ AJEST2013.1584

Mahmoud, M. I., Duker, A., Conrad, C., Thiel, M., and Ahmad, H. S. (2016). Analysis of settlement expansion and urban growth modelling using geoinformation for assessing potential impacts of urbanization on climate in Abuja City, Nigeria. Remote Sensing, 8(220), 1-24. https://doi.org/10.3390/ rs8030220

Mallupattu, P. K., Reddy, J., and Reddy, S. (2013). Analysis of Land Use / Land Cover Changes Using Remote Sensing Data and GIS at an Urban Area, Tirupati, India. The Scientific World Journal, 2013, 1-6. https://doi.org/http:// dx.doi.org/10.1155/2013/268623

McGovern, M., and Pasher, J. (2016). Canadian urban tree canopy cover and carbon sequestration status and change 1990-2012. Urban Forestry and Urban Greening, 20(1), 227-232. https:// doi.org/10.1016/j.ufug.2016.09.002

Mekonnen, Z., Tadesse, H., Woldeamanuel, T., Asfaw, Z., and Kassa, H. (2018). Land use and land cover changes and the link to land degradation in Arsi Negele district, Central Rift Valley, Ethiopia. Remote Sensing Applications: Society and
Environment, 12, 1-9. https://doi.org/10.1016/ j.rsase.2018.07.012

Mudau, N., Mhangara, P., and Gebreslasie, M. (2014). Monitoring urban growth around Rustenburg, South Africa, using SPOT 5. South African Journal of Geomatics, 3(2), 185-196. https:// doi.org/DOI: http://dx.doi.org/10.4314/sajg.v3i2.5

National Bureau of Statistics. (2016). Annual Abstract of Statistics (Vol. 1, Issue July).

Nigeria Population Council. (2007). Report of Nigeria's National Population Commission on the 2006 Census. In Population and Development Review (Vol. 33, Issue 1). https:// doi.org/10.2307/25434601

Nkeki, F. N. (2016). Spatio-temporal analysis of land use transition and urban growth characterization in Benin metropolitan region, Nigeria. Remote Sensing Applications: Society and Environment, 4, 119-137. https://doi.org/10.1016/ j.rsase.2016.08.002

Nlend, B., Celle-Jeanton, H., Huneau, F., Ketchemen-Tandia, B., Fantong, W. Y., Boum-Nkot, S. N., and Etame, J. (2018). The impact of urban development on aquifers in large coastal cities of West Africa: Present status and future challenges. Land Use Policy, 75, 352-363. https://doi.org/10.1016/ j.landusepol.2018.03.007

Nor, A. N. M., Corstanje, R., Harris, J. A., and Brewer, T. (2017). Impact of rapid urban expansion on green space structure. Ecological Indicators, 81(June), 274-284. https:// doi.org/10.1016/j.ecolind.2017.05.031

Ogunjobi, K. O., Adamu, Y., Akinsanola, A. A., and Orimoloye, I. R. (2018). Spatio-temporal analysis of land use dynamics and its potential indications on land surface temperature in Sokoto Metropolis, Nigeria. Royal Society Open Science, 5(18066), 1 -10. https://doi.org/10.1098/rsos.180661

Pellikka, P. K. E., Heikinheimo, V., Hietanen, J., Schäfer, E., Siljander, M., and Heiskanen, J. (2018). Impact of land cover change on aboveground carbon stocks in Afromontane landscape in Kenya. Applied Geography, 94, 178-189. https:// doi.org/10.1016/j.apgeog.2018.03.017

Peng, W., Wang, G., Zhou, J., Zhao, J., and Yang, C. (2015). Studies on the temporal and spatial variations of urban expansion in Chengdu, western China, from 1978 to 2010. Sustainable Cities and Society, 17, 141-150. https://doi.org/10.1016/ j.scs.2015.03.004

Pham, V. C., Pham, T. T. H., Tong, T. H. A., Nguyen, T. T. H., and Pham, N. H. (2015). The conversion of agricultural land in the peri-urban areas of Hanoi (Vietnam): patterns in space and time. Journal of Land Use Science, 10(2), 224-242. https://doi.org/10.1080/1747423X.2014.884643

Rawat, J. S., Biswas, V., and Kumar, M. (2013). Changes in land use/ cover using geospatial techniques: A case study of Ramnagar town area, district Nainital, Uttarakhand, India. Egyptian Journal of Remote Sensing and Space Science, 16(1), 111-117. https://doi.org/10.1016/j.ejrs.2013.04.002

Rwanga, S. S., and Ndambuki, J. M. (2017). Accuracy Assessment of Land Use/Land Cover Classification Using Remote Sensing and GIS. International Journal of Geosciences, 8, 611-622. https://doi.org/10.4236/ijg.2017.84033

Sanni, M., Odekunle, T. O., and Adesina, F. A. (2012). Climate Change and the Sustainable Use of Water Resources (W. L. Filho (ed.)). Springer-Verlag Berlin Heidelberg. https:// doi.org/10.1007/978-3-642-22266-5

Schneider, A., Logan, K. E., and Kucharik, C. J. (2012). Impacts of Urbanization on Ecosystem Goods and Services in the U.S. Corn Belt. Ecosystems, 15(4), 519-541. https:// doi.org/10.1007/s10021-012-9519-1

Shamaki, M. A., and Dankani, I. M. (2012). Urban growth and development of the Sokoto urban area: implication for sustainable development. In D. A. Abdulrahman, I. S. Ogundiya, T. Garba, and I. M. Dankani (Eds.), 50 Years of Nigeria's Nationhood: Issues and Challenges for Sustainable Development and (pp. 326-340). Crown F. Publishers. 
Shi, X., and Xue, B. (2017). Parallelizing maximum likelihood classification on computer cluster and graphics processing unit for supervised image classification. International Journal of Digital Earth, 10(7), 737-748. https:// doi.org/10.1080/17538947.2016.1251502

Sinha, P., Verma, N. K., and Ayele, E. (2016). Urban Built-up Area Extraction and Change Detection of Adama Municipal Area using Time-Series Landsat Images. International Journal of Advanced Remote Sensing and GIS, 5(1), 1886-1895. https:// doi.org/10.23953/cloud.ijarsg.67

Sory, I. T., Douglas, A. S., Hsiao-chien, S., John, W., and David, L.C. (2018). Land cover and land use change analysis using multi-spatial resolution data and object-based image analysis. Remote Sensing of Environment, 210, 259-268. https:// doi.org/10.1016/j.rse.2018.03.023

Sowmya, D. R., Deepa, S. P., and Venugopal, K. R. (2017). Remote Sensing Satellite Image Processing Techniques for Image Classification: A Comprehensive Survey. International Journal of Computer Applications, 161(11), 24-37. https:// doi.org/10.5120/ijca2017913306

United Nations. (2014). World Urbanization Prospects 2014. In Demographic Research. https://doi.org/(ST/ESA/SER.A/366)

Wali, M. A. (2010). Dynamics of policy implementation in nigeria $\bigotimes:$ the case of Sokoto state. iUniverse Inc.

Wang, Y. (2012). Land cover change and conservation of protected lands in urban and suburban settings. In Y. Wang (Ed.), Remote Sensing of Protected Lands (p. 588). Taylor and Francis Group.
Wezel, A., and Lykke, A. M. (2006). Woody vegetation change in Sahelian West Africa: Evidence from local knowledge. Environment, Development and Sustainability, 8(4), 553-567. https://doi.org/10.1007/s10668-006-9055-2

$\mathrm{Wu}, \mathrm{Y}$., Li, S., and Yu, S. (2016). Monitoring urban expansion and its effects on land use and land cover changes in Guangzhou city, China. Environmental Monitoring and Assessment, 2016, 188-54. https://doi.org/10.1007/s10661-015-5069-2

Wulder, M. A., Masek, J. G., Cohen, W. B., Loveland, T. R., and Woodcock, C. E. (2012). Opening the archive: How free data has enabled the science and monitoring promise of Landsat. Remote Sensing of Environment, 122, 2-10. https:// doi.org/10.1016/j.rse.2012.01.010

Xiaowei, Y., Wang, Z., and Wang, H. (2015). Impact of Urbanization and Land-Use Change on Surface Climate in Middle and Lower Reaches of the Yangtze River, 1988-2008. Advances in Meteorology, 2015, 1-10. https:// doi.org/10.1155/2015/395094

Zhang, D., Zheng, H., He, X., Ren, Z., Zhai, C., Yu, X., Mao, Z., and Wang, P. (2016). Effects of forest type and urbanization on species composition and diversity of urban forest in Changchun, Northeast China. Urban Ecosystems, 19(1), 455 -473. https://doi.org/10.1007/s11252-015-0473-5 